Forrester, J.S., Diamond, G., McHugh, T.J. \& Swan, H.J.C. (1971) Filling pressures in the right and left sides of the heart in acute myocardial infarction. A reappraisal of central-venous-pressure monitoring. New England Journal of Medicine, 285, 190.

Leaf, A., Bartter, F.C., Santos, R.F. \& Wrong, O. (1953) Evidence in man that urinary electrolyte loss induced by pitressinis a function of water retention. Journal of Clinical Investigation, 32, 868.

Leaf, A., Chatillon, J.Y., Wrong, O. \& Tuttle, E.P.
(1954) The mechanism of the osmotic adjustment of the body cells. Journal of Clinical Investigation, 33, 952.

RowntreE, L.G. (1922) The water balance of the body. Physiological Reviews, 2, 116.

WynN, V. \& RoB, C.G. (1954) Water intoxication. Differential diagnosis of the hypotonic syndromes. Lancet, i, 587.

WynN, V. \& Houghton, B.J. (1957) Observations in man upon the osmotic behaviour of the body cells after trauma. Quarterly Journal of Medicine. New Series, XXVI, 375.

\title{
Contraceptive pill-induced porphyria cutanea tarda presenting with onycholysis of the finger nails
}

\author{
J. P. H. BYRne \\ M.A., M.B., M.R.C.P.(I), M.R.C.P.(U.K.)
R. P. R. DAWBER
M.B., M.R.C.P. \\ North Staffordshire Hospital Centre
}

J. M. Boss

M.B., Ch.B.

\begin{abstract}
Summary
A case of porphyria cutanea tarda induced by oral contraceptive pill therapy is reported, and its unusual presenting sign of onycholysis of the finger nails is noted. Reference is made to the rarity of nail changes in porphyria and the regression of the onycholysis in the patient following therapy is outlined.
\end{abstract}

\section{Introduction}

The porphyrias encompass a group of metabolic disorders, genetic and acquired, characterized by the excess production of porphyrins or their precursors. With the exception of acute intermittent porphyria, cutaneous manifestations, resulting from exposure to light, are prominent in these disorders and include oedema, vesicle and bulla formation, increased skin fragility, pigmentation, scarring and atrophy of the light-exposed surfaces of the body, namely the face, neck and dorsa of the hands.

Nail changes may occur in porphyria especially in the acute phase (Dean, 1975, personal communication) but the rarity of nail dystrophy is attested to by the absence of any reference to nail lesions occurring in porphyria in two major dermatological textbooks (Samman, 1972; Cairns, 1972).

Requests for reprints: Dr J. P. H. Byrne, Department of Dermatology, King's College Hospital, Denmark Hill, London SE5 9RS.
Among the nail changes that may be seen in porphyria are opaqueness, brown and bluish-grey discolorations, and loss of the lunule, but such changes are exceptionally rare in porphyria cutanea tarda compared with erythropoietic porphyria (Degos, 1970). Onycholysis, i.e. separation of the distal nail plate from its bed, has been observed in symptomatic porphyria (Tschudy, Magnus and Kalivas, 1971).

A case is reported of porphyria cutanea tarda in a young woman who had been taking an oral contraceptive agent, Norinyl-1, for 18 months, and who presented initially to her general practitioner with discoloration of her finger nails due to onycholysis.

\section{Case report}

The patient was a 21-year-old married policewoman, with no previous history of a skin disorder either in herself or her family. In January, 1974, she noted brownish discoloration of the distal parts of some of her finger nails and thumbs. She was referred to the dermatology clinic by her general practitioner where the nail discoloration was diagnosed as onycholysis. In addition, numerous vesicles, erosions and pitted scars were noted on the dorsa of the hands and face, together with hypertrichosis of the face. Associated with these signs was a feeling of soreness in these regions on exposure to light. There were no symptoms referable to the abdominal or 


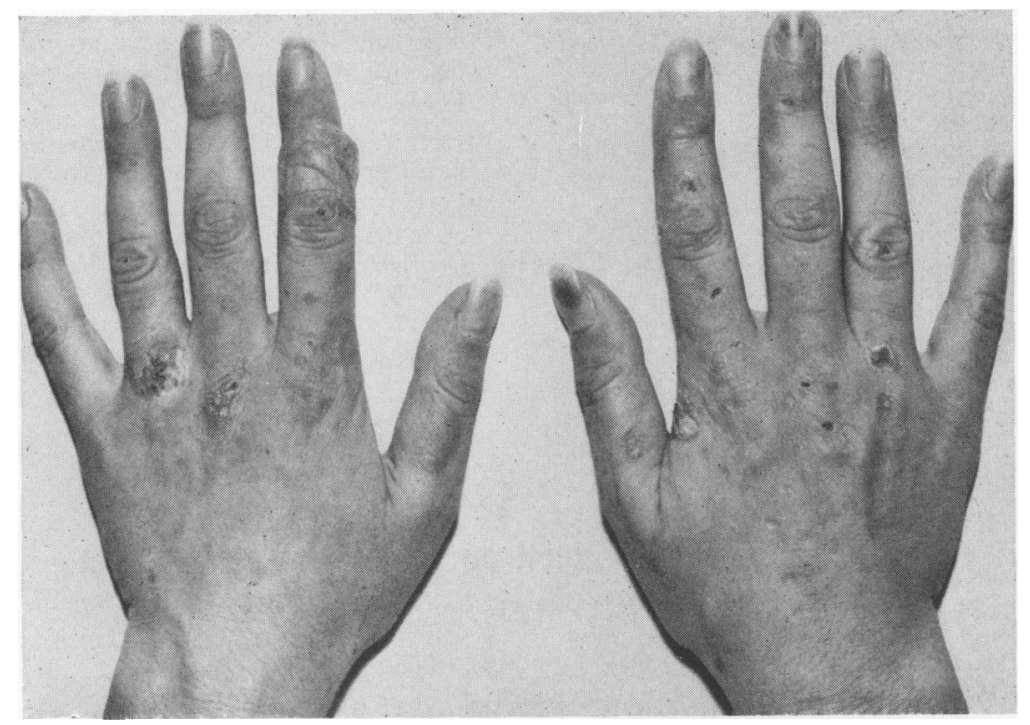

FIG. 1. Photograph showing a ruptured bulla, erosions, scarring and onycholysis of the right index, middle finger and both thumb nails.

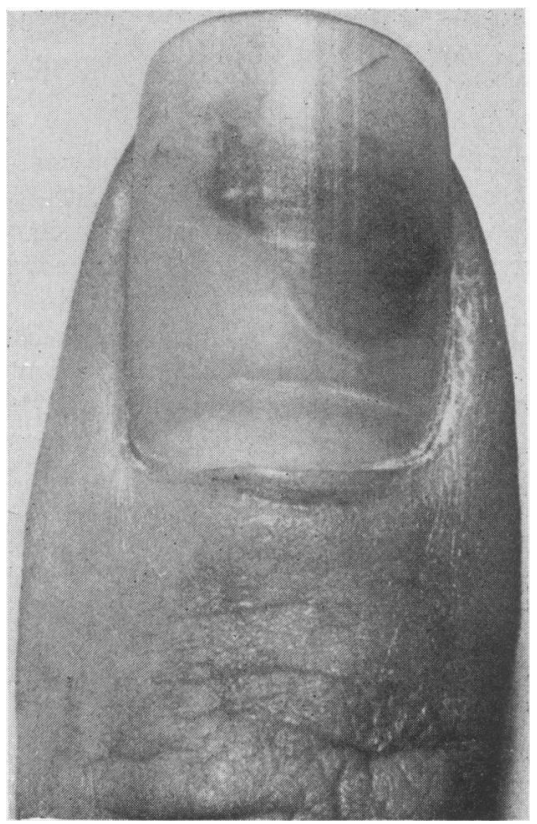

Fig. 2. Close-up view of right thumb demonstrating typical onycholysis.

neurological systems. A provisional diagnosis of porphyria, either cutanea tarda or variegata, was made and the patient was admitted for further investigations.

Up to this time, the patient had been on no medi- cation other than Norinyl-1, an oral contraceptive pill containing norethisterone BP $1 \mathrm{mg}$ and mestranol BP $50 \mu \mathrm{g}$ in each tablet.

No member of her family ever had a similar con-ce dition. The patient admitted to a modest intake of alcohol. Detailed examination revealed a fit but anxious young woman. On the hands were numerous erosions, vesicles and small pitted scars. There was onycholysis of both thumb nails, right index and middle finger nails (Figs 1 and 2). On the face there was a fine vellus growth of hair on both cheeks, together with scars and ruptured vesicles. There was no other detectable physical abnormality, especially no hepatomegaly.

Investigations revealed a haemoglobin of 14.9 $\mathrm{g} / 100 \mathrm{ml}$, a serum iron of $225 \mu \mathrm{g} / 100 \mathrm{ml}$, and total iron binding capacity of $300 \mu \mathrm{g} / 100 \mathrm{ml}$. The prothrombin index was $87 \%$ and partial thromboplastin time $46.0 \mathrm{sec}$ (control $=38.5 \mathrm{sec}$ ).

A biochemical screen revealed a serum glutamic oxaloacetic transminase of $118 \mathrm{mu} / \mathrm{ml}$ (normal 7-40 $\mathrm{mu} / \mathrm{ml}$ ) and alkaline phosphatase $130 \mathrm{mu} / \mathrm{ml}$ (normal 30-85 mu/ml). The serum bilirubin, total proteins and albumin were within normal limits. A plasma BSP dye test showed $28 \%$ retention at $45 \mathrm{~min}$ after injection of the dye.

Urine and blister fluid gave a pink fluorescence under a Woods Lamp. Porphobilinogen was not detected in the urine. The red cells did not fluoresce. There was a weak positive anti-smooth muscle antibody titre, but tests for LE cells and anti-nuclear factor were negative. A liver biopsy revealed a vast 


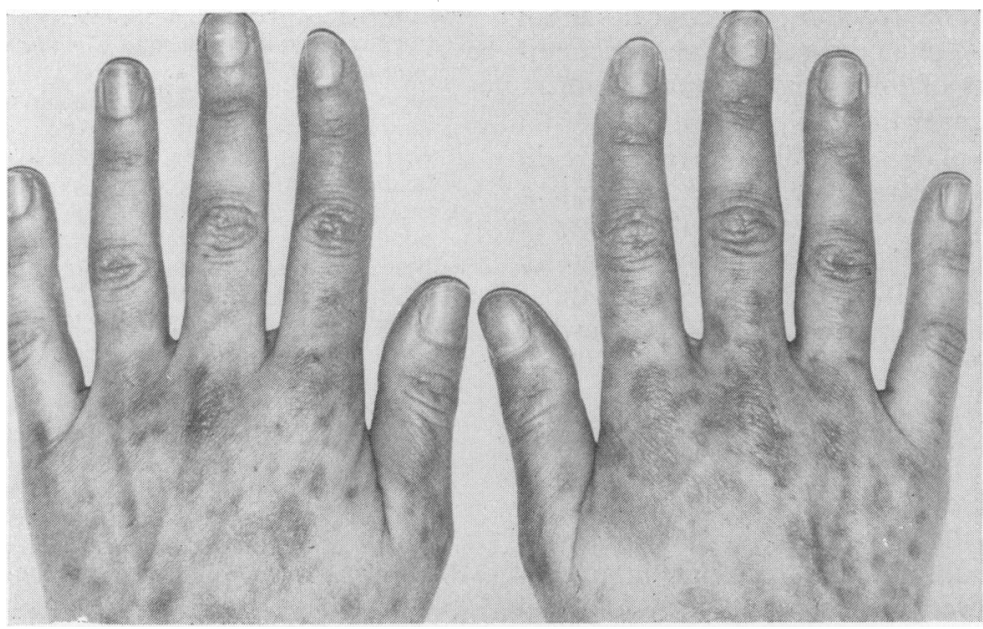

FIG. 3. Post-therapy photograph showing pigmentation and scarring of the skin with normal appearance of the nails.

TABLE 1. Results of porphyrin analyses.

\begin{tabular}{|c|c|c|}
\hline \multicolumn{2}{|c|}{ Urine porphyrins $/ 24 \mathrm{hr}$} & \multirow{2}{*}{$\begin{array}{c}\text { Normal range }(\mu \mathrm{g}) \\
(0-283) \\
(0-40)\end{array}$} \\
\hline $\begin{array}{l}\text { Coproporphyrin } \\
\text { Uroporphyrin }\end{array}$ & $\begin{array}{c}633 \cdot 6 \mu \mathrm{g} \\
14.79 \mathrm{mg}\end{array}$ & \\
\hline \multicolumn{3}{|c|}{ Faecal porphyrins/g dry weight } \\
\hline $\begin{array}{l}\text { Coproporphyrin } \\
\text { Protoporphyrin } \\
\text { 'X' porphyrin } \\
\text { 'X' porphyrin cor } \\
\text { of uroporphy! }\end{array}$ & $\begin{array}{l}135 \mu \mathrm{g} \\
40 \cdot 3 \mu \mathrm{g} \\
105 \mu \mathrm{g} \\
\text { sisted predominantly } \\
\text { in. }\end{array}$ & $\begin{array}{l}(0-50) \\
(0-113) \\
(0-20)\end{array}$ \\
\hline
\end{tabular}

excess of iron in the hepatocytes and Kupffer cells but no other abnormality was seen. Biopsy of a vesicle on the hand revealed a rim of PAS-positive diastase resistant material around a blood vessel.

Detailed stool and urine porphyrin analyses are given in Table 1.

Consequently a diagnosis of porphyria cutanea tarda was made in view of the clinical features and laboratory findings of raised urinary and faecal uroporphyrins and coproporphyrins, negative testing for porphobilinogen, raised serum iron level, abnormal liver function tests and hepatic siderosis on histology.

Therapy using ordinary sodium bicarbonate to alkalinize the urine and thereby increase porphyrin excretion (Copeman, 1970) was unsuccessful. Consequently venesection therapy was introduced, and 41 of blood were removed in all over a period of 4 months, $500 \mathrm{ml}$ being removed fortnightly. As a result of this treatment, together with abstention from the 'pill', there was a dramatic improvement in the patient's symptoms and signs, namely no further vesiculation, scarring or undue skin fragility. Fortunately too, the patient's nails rapidly regained their normal appearance, the new nail growth leading to extrusion of the onycholytic nails (Fig. 3 ).

\section{Discussion}

Porphyria cutanea tarda is one of the commoner types of porphyria, and in the United Kingdom is probably second only in frequency to erythropoietic protoporphyria (Magnus, 1974). Whilst typically occurring in middle-aged males with a history of alcohol abuse (Cairns, 1972; Tschudy, Magnus and Kalivas, 1971; Walsh et al., 1970), there are an increasing number of reports recording the onset of porphyria cutanea tarda following oestrogen therapy (Walshe, 1963; Roenigk and Gottlob, 1970; Behm and Unger, 1974). It is felt that the above case, in view of her age, history of oestrogen therapy and lack of heavy alcoholic intake, is a further example of contraceptive pill-induced porphyria cutanea tarda.

Whilst it is possible that the patient's signs and symptoms may have regressed merely by stopping therapy, her improvement, still apparent 9 months following venesection, is considered to be due to phlebotomy. Numerous authors have recorded the efficacy of phlebotomy in porphyria cutanea tarda (Ippen, 1960; Epstein and Redeker, 1968; Baker and Turnbull, 1969).

Venesections aid PCT by removing hepatic cellular iron which is aggravating an underlying biochemical anomaly (Turnbull, 1974). Especially gratifying to the patient was the return to normal of her finger nails, as the onycholysis was a considerable embarrassment in view of her occupation. The porphyrins, known photosensitizing agents, are found in the skin and in the presence of light, are responsible for a reaction which leads to oedema, and 
vesiculation, etc. The reaction, which can entail release of enzyme-damaging systems and accumulation of mediators of inflammation, may result in blister formation under the nail plate, causing distal separation of the plate, i.e. photo-onycholysis, in view of the necessity of light exposure in initiating the reaction. However, the rarity of nail changes in the cutaneous porphyrias would suggest that an inherent nail abnormality is present in only those porphyriacs who develop nail lesions. A somewhat analogous situation is the photo-onycholysis following tetracycline therapy (Orentreich, Harber and Tromovitch, 1961; Segal, 1963). It would appear, in view of the rarity of photosensitivity to tetracycline, that the tetracycline derivative accumulates in the nail plates and there initiates a photo-allergic reaction on exposure to light resulting in photoonycholysis. However, the exact pathophysiological basis of photo-onycholysis remains conjectural in the porphyrias.

In conclusion, an additional case is here reported of contraceptive pill-induced porphyria cutanea tarda which presented with onycholysis of the nails. The beneficial effect of phlebotomy on the patient's symptoms and signs is described. On the basis of the findings the patient has been advised to avoid all oestrogen-containing preparations and to use an alternative form of contraception in the hope that subsequent light exposure will not provoke a further episode of porphyria cutanea tarda.

\section{Acknowledgments}

It is a pleasure to acknowledge the assistance of Mrs Maureen Doyle, St John's Hospital for Diseases of the Skin, London, the help of the Department of Medical Illustration, and the secretarial assistance of Miss Stella Collins.

\section{References}

BAKer, H. \& Turnbull, A. (1969) Porphyria cutanea tarda treated by repeated venesection: clinical and biochemical response. Proceedings of the Royal Society of Medicine, 62, 14.
BEHM, A.R. \& UNGER, W.P. (1974) Oral contraceptives and porphyria cutanea tarda. Canadian Medical Association Journal, 110, 1052.

CAIRNS, R.J. (1972) Hepatic porphyrias, In: Textbook of Dermatology (Ed. by A. Rook, D.S. Wilkinson and F. J. Ebling), 2nd edn, p. 1832. Blackwell Scientific Publications, Oxford.

Copeman, P.W.M. (1970) Porphyria : successful treatment by alkalinisation of urine with sodium bicarbonate assessed by experimental suction blister apparatus. British Journal of Dermatology, 82, 385.

Degos, R. (1970) Porphyries Cutanées. Collection Médicochirurgicale à Revision Annuelle. Editions Médicales Flammarion, p. 393.

Epstein, J.H. \& Redeker, A.G. (1968) Porphyria cutanea tarda: a study of the effect of phlebotomy. New England Journal of Medicine, 279, 1301.

IPPEN, H. (1960) Entstehung und Behandlung der Porphyria cutanea tarda (chronische, hepatische porphyrie). Vorlaufige Mitteilung. Klinische Wochenschrift, 38, 89.

MAGNUS, I.A. (1974) Porphyria as a model of abnormal skin sensitivity, Parkes-Weber Lecture. In: 10th Symposium on Advanced Medicine, Royal College of Physicians, London. Pitman Medical Publishing Co. Ltd, London.

Orentreich, N., Harber, L.C. \& Tromovitch, T.A. (1961) Photosensitivity and photo-onycholysis due to demethylchlortetracycline. Archives of Dermatology, 83, 730.

RoenigK, H.H., JR \& GotTlob, M.E. (1970) Estrogeninduced porphyria cutanea tarda. Report of three cases. Archives of Dermatology, 102, 260.

Samman, P.D. (1972) The Nails in Disease, 2nd edn. William Heinemann Medical Books Ltd, London.

SEgal, B.M. (1963) Photosensitivity, nail discoloration and onycholysis: side effects of tetracycline therapy. Archives of Internal Medicine, 112, 165.

Tschudy, D.P., Magnus, I.A. \& Kalivas, J. (1971) The porphyrias. In: Dermatology in General Medicine (Ed. by T.B. Fitzpatrick, K.A. Arndt, W.H. Clark et al.), p. 1158. McGraw Hill Book Co. Ltd, New York.

Turnbull, A.L. (1974) Iron metabolism in the porphyrias. In: 10th Symposium on Advanced Medicine, Royal College of Physicians, London. Pitman Medical Publishing Co. Ltd, London.

Walsh, J.R., Lobitz, W.C., Mahler, D.J. \& Kingery, F.A.J. (1970) Phlebotomy therapy in cutaneous porphyria: effect on iron and trace metals. Archives of Dermatology, $107,167$.

Walshe, M. (1963) Porphyria cutanea tarda associated with oestrogen therapy for prostatic carcinoma. British Journal of Dermatology, 75, 298. 